\title{
Charting a Course of Development through Proper Technical, Technological and Engineering Education
}

\author{
Olawale Olaniyi Emmanuel Ajibola \\ University of Lagos, Lagos, Nigeria
}

\begin{abstract}
Knowledge refers to the possession of information, facts, ideas, truth or principles. The imparting and acquiring of knowledge through teaching and learning refer to education. The nucleus of education is knowledge. A well-directed education is the process that yields knowledge. Engineering is the application of science in the design, planning, construction and maintenance of manufactured entity while Engineering education is the training of engineers for the purpose of initiating, facilitating and implementing the technological development of a Nation. Engineering uses scientific ideas to develop technology but technology provides the ingredient for Engineering. Technical education engenders formal preparation of Technicians for occupations between the skilled trades and the professions based on underlying sciences and supporting mathematics as well as methods, skills, materials, and processes of a specialized field of technology. In this work, the roles of these tier of education in the development of a nation was discussed in relation to the existing developmental efforts made towards achieving technological advancement in Nigeria. It is hoped that the policy makers in Nigeria will find the paper useful for the betterment of hoi polloi by charting a course of developing the entity called Nigeria through well-found technical, technological and engineering education.
\end{abstract}

Keywords: Course of development, technical education, technological education, engineering education,

\section{Introduction}

Technology refers to the application of scientific knowledge to the practical aims of human life or, as it is sometimes phrased, to the change and manipulation of the human environment, Britannica (2008). It is the study, development and application of devices, machines and techniques for manufacturing and productive processes; the sum of a society's or culture's practical knowledge, especially with reference to its material culture, Microsoft Encarta (2009). Technology could also be conceived as a method or methodology that applies technical knowledge or tools. In the most casual form, it could mean machines, equipment and systems considered as a unit. Technology is the nucleus of the subject matter of this paper. Technology is sometimes confused with engineering; it is often mistaken for machinery or computing device but Technology embraces more than machines as it also involves processes. Engineering uses scientific ideas to develop technology, Falade, (2010). In addition, the scenario is the same for technological and engineering education.

Technical education is the academic and vocational preparation of students for jobs involving applied science and modern technology. It emphasizes the understanding and practical application of basic principles of science and mathematics, rather than the attainment of proficiency in manual skills that is properly the concern of vocational education. Technical education has as its objectives the preparation of graduates for occupations that are classed above the skilled crafts but below the scientific or engineering professions. People so employed are frequently called technicians. Technical education is distinct from professional education, which places major emphasis upon the theories, understanding, and principles of a wide body of subject matter designed to equip the graduate to practice authoritatively in such fields as science, engineering, law, or medicine. Technical occupations are vital in a wide range of fields, including agriculture, business administration, computers and data processing, education, environmental and resource management, graphic arts and industrial design, and health and medicine; technical educational curricula are correspondingly specialized over a broad range of disciplines. Technical education is typically offered in posthigh-school curricula that are two years in length, but they are not designed to lead to a bachelor's degree, and are offered in a wide variety of institutions, such as technical institutes, junior colleges, vocational schools, and regular colleges and universities, Britannica (2008). 
In the early millennia of human existence, a craft was acquired in a lengthy and laborious manner by serving with a master who gradually trained the initiate in the arcane mysteries of the skill. Such instruction, set in a matrix of oral tradition and practical experience, was frequently more closely related to religious ritual than to the application of rational scientific principles. Craft training was institutionalized in Western civilization in the form of apprenticeship, which has survived into the 20th century as a framework for instruction in technical skills. Increasingly, however, instruction in new techniques has required access both to general theoretical knowledge and to realms of practical experience that, because of their novelty, were not available through traditional apprenticeship. Thus, the requirement for a significant proportion of academic instruction has become an important feature of most aspects of modern technology. This has accelerated the convergence between science and technology in the 19th and 20th centuries and has created a complex system of educational awards representing the level of accomplishment from simple instruction in schools to advanced research in universities. French and German academies led in the provision of such theoretical instruction, while Britain lagged somewhat in the 19th century, owing to its long and highly successful tradition of apprenticeship in engineering and related skills. However, by the 20th century all the advanced industrial countries, including newcomers like Japan, had recognized the crucial role of a theoretical technological education in achieving commercial and industrial competence. The application of science in the design, planning, construction and maintenance of manufactured entity is called Engineering. Engineering education is the training of engineers for the purposes of initiating, facilitating and implementing the technological development of a nation, Ajibola (2011). It is a very important area of human endeavour in the sense that engineering is the life support for developing, growing and maintaining the economy of any nation irrespective of the level of economic advancement attained by the nation. Engineering is the application of Science for the efficient utilization of natural resources to produce wealth. It has also been defined as the "application of laws governing forces and materials of nature through research, design, management and construction for the benefit of mankind, Alabe (2009).

\section{Engineering Education and Practice in the United States}

The recognition of the importance of technological education, however, has never been complete in Western civilization, and the continued coexistence of other traditions has caused problems of assimilation and adjustment. The British author Snow drew attention to one of the most persistent problems in his perceptive essay, The Two Cultures (1959), in which he identified the dichotomy between scientists and technologists on the one hand and humanists and artists on the other as one between those who did understand the second law of thermodynamics and those who did not, causing a sharp disjunction of comprehension and sympathy. Arthur Koestler put the same point in another way by observing that the traditionally humanities-educated Western man is reluctant to admit that a work of art is beyond his comprehension, but he will cheerfully confess that he does not understand how his radio or heating system works. Koestler characterized such a modern man, isolated from a technological environment that he possesses without understanding, as an "urban barbarian." Yet the growing prevalence of "black-box" technology, in which only the rarefied expert is able to understand the enormously complex operations that go on inside the electronic equipment, makes it more and more difficult to avoid becoming such a "barbarian." The most helpful development would seem to be not so much seeking to master the expertise of others in our increasingly specialized society, as encouraging those disciplines that provide bridges between the two cultures, and here there is a valuable role for the history of technology. America, the prime of technology, has an outstanding history of technology. The case of God's own country is a pointer to the fact that Nigeria is not yet prepared to plan for the much desired technological development and so the dream of vision 20:2020 will ever remain a mirage because none of the indicators for the take-off of successful planning has been put in place. To start with, Nigeria cannot make an accurate statement about her population. The United States of America that is primed as the world's best economy and the world's power is no doubt the most advanced country in the world. Despite her technological prowess, the government of the United States in recognition of necessity to further climb the ladder of development attempted to redefine the blueprint of her economy. The government commenced her planning from the basis; the Committee on the Education and Utilization of the Engineer to investigate educational aspects of the preparation of engineers in the United States was commissioned to provide the springboard to kick-start the new phase of development in technology. 
One of the four panels established by the committee is the panel on Technological Education, Engineering Technology Education (1985). The recommendations of the panel as contained in the executive summary of their nine-chapter report include:

- Student chapter of engineering related associations be encouraged by the associations and faculty sponsors in order to provide students with additional contacts and activities with national societies and their representatives

- Cooperative education in all of its forms should be expanded through greater industrial, institutional, and governmental support, with faculty industry linkages being encouraged

- "Hallmark" programs in engineering technology should be identified, publicized, and supported nationally

- Appropriate accrediting agencies should play a greater role in efforts to increase the quality of engineering technology programs

- Students should be prepared for and encouraged to seek technician certification

- Professional registration or certification of engineering technology faculty should be encouraged

- Labor statistics on enrolment, degrees, and salaries should be maintained at the college, state and national levels.

- Finally, the panel considered resource allocation pattern of various institutions as regards areas of engineering technology, and the following recommendations were developed:

- Institutions should plan to develop a limited number of "centres of emphasis" in subspecialties

- Continuing efforts should be made to upgrade laboratories and shops, recognizing the importance they play in the education of engineering technicians and technologists

- Linkages with industry should be developed to share specialized laboratory and shop facilities, both in industry and on campus.

Other recommendations referred to as "specific recommendations" were not considered this paper for lack of space. However, one thing that is sure is that these recommendations among others shall be implemented to the letter because the factor of "corruption" will not come into play in the US. The consideration here is that 'if a country like the US could still place emphasis on all the facets of Engineering education with special consideration for technical education' then Nigeria should as a matter of urgency revive engineering education at all levels

\section{Engineering Education and Practice in Nigeria}

The ultimate goal of any nation striving to develop its technological prowess concerns the quality of life of her citizenry hence the relationship between technology and the society cannot be overemphasized. There is no doubt that technology has brought a higher standard of living to people in advanced countries, just as it has enabled a rapidly rising population to subsist in the developing countries. It is the prospect of rising living standards that makes the acquisition of technical competence so attractive to every country the world over. Although it is a worthy desire to possess a comfortable sufficiency of material goods, and leisure for recreative purposes, the quality of a full life in any human society has other even more important prerequisites, such as the possession of freedom in a law-abiding community and equality before the law. Certainly, highly oppressive regimes have used technological devices to suppress individual freedom and to secure obedience to the state especially in Africa. However, high technological competence requires a high level of educational achievement by a significant proportion of the community holds out the hope that a society that is well educated will not long endure constraints on individual freedom and initiative that are not self-justifying. In other words, the high degree of correlation between technological success and educational accomplishment suggests a fundamental democratic bias about modern technology. It may take time to become effective, but given sufficient time without a major political or social disruption and a consequent resurgence of national assertiveness and human selfishness, there are sound reasons for hoping that technology will bring the people of the world into a closer and more creative community. And Nigeria must not be left out in the scheme of things. The hope of anybody who takes a long view of the history of technology as one of the most formative and persistently creative themes in the development of humankind from the Palaeolithic cave dwellers of antiquity to the dawn of the space age in the 20th century is deeprooted in the ability of technology to promote the quality of life. Above all other perceptions of technology, the threshold of space exploration on which mankind stands at the end of the 20th century provides the most 
dynamic and hopeful portent of human potentialities. Even while the threat of technological self-destruction remains ominous, and the problems of population control and ecological imbalance cry out for satisfactory solutions, man has found a clue of his own future in terms of a quest to explore and colonize the depths of an infinitely fascinating universe. As yet, only a few visionaries have appreciated the richness of this possibility, and their projections are too easily dismissed as nothing more than imaginative science fiction. However, in the end, if there is to be a long run for our uniquely technological but willful species, the future depends upon the ability to acquire such a cosmic perspective, so it is important to recognize this now and to begin the arduous mental and physical preparations accordingly. The words of Arthur C. Clarke, one of the most perceptive of contemporary seers, in his Profiles of the Future (1962), are worth recalling in this context. Thinking ahead to the countless eons that could stem from the remarkable human achievement summarized in the history of technology, he surmised that the all-knowing beings who may evolve from these humble beginnings may still regard our own era with wistfulness: "But for all that, they may envy us, basking in the bright afterglow of Creation; for we knew the Universe when it was young.", Britannica 8.0 (2008).

There are so many technical institutions in Nigeria today; so many technical institutions have been developed at the technical college, polytechnic and university levels. However, many of these institutions do not have adequate infrastructure. There are no teachers of high quality; even the motivation among students is very low because of the societal disdain that does not accord the necessary recognition to technical education such that many students do not want to attend technical institutions, Aina (2011). Other identifiable problems facing the trio of technical, technological and engineering education as enumerated by Ajibola, (2011) in his paper title "an expository analysis of problems and prospects of engineering education in Nigeria" are:

- Inadequate Funding from the Federal Government

- Inadequate Government Allocation to Education in Nigeria (1970 -2002)

- Inadequacy of the Academic Content

- Staffing Problem

- Poor Infrastructural Facilities

- The Disconnect between Classroom and the Industry

- Intermittent Parental Intrusion into the Educational Structure

- Students' Lack of Will to Invest in their own Future

- Negative Influence of Political Office Holders on On-coming Generation

- The Erasure of Moral Fabric in Africa

- The Ill-implemented Industrial Training Programme

Our reward system is also faulty. A psychological reward is a process that reinforces behavior; something that, when offered, causes a behavior to increase in intensity. Reward is an operational concept for describing the positive value an individual ascribes to an object, behavioral act or an internal physical state. Natural rewards include those that are necessary for the survival of species, such as eating, drinking, sex, and fighting. Secondary rewards derive their value from the primary reward, and include shelter, money, pleasant touch, beauty, music, etc. The functions of rewards are based directly on the modification of behavior and indirectly on the sensory properties of rewards, Wikipedia (2011). For instance, altruism may induce a larger psychological reward, although it does not cause sensations. Rewards are generally considered more effective than punishment in enforcing positive behavior. There is no doubt that it is the best brains that study technological based subjects. However, the reward system in Nigeria is to say the list, awkward. Remunerations and other inducing factors for engineering related disciplines are embarrassingly insulting even in an engineering firm:

- While an accountant is placed on a salary of N250, 000.00 and above, the engineering graduate is expected to receive $\mathrm{N} 15,000.00$.

- His office is housed in a wooden carton whereas his counterpart who read Personnel management is housed in the Management building with full blast air-conditioning system.

- He does not get promoted at the same time as his counterpart Legal department of the same establishment, and

- The responsibility of maintenance of all the facilities, which others enjoy with an exception to him, rests on his shoulders. 
In his paper titled “Technical and Vocational Education: Key to Nigeria's Development", Dike (2009) did an extensive exposition of the implications of the deletion of technical education from the educational structure of a hitherto developing nation called Nigeria. He reiterated the fact that our engineering educational system has collapse for lacking in foundation. "While technical and vocational education has continued to strive in many societies Nigeria has neglected this aspect of education. Consequently, the society lacks skilled technicians: bricklayers, carpenters, painters, and auto mechanics; medical laboratory and pharmaceutical technicians, electrical/electronic technicians and skilled vocational nurses". The consequence of the aforementioned is the dearth of technically skilled labour, which translates to the lack of lubricant necessary to facilitate the smooth running of the engine of development in Nigeria. The aftermath of excluding technical education in the scheme of development in Nigeria is the collapse of the technological education and by implication, the university education. The absence of the technical inputs from the products of technical and vocational institutions in the graduates from both institutions has reduced such graduates to diploma/degree certificates carrying apprentices. The shabby performance of builders; building technologists, mason and bricklayers is no longer news. That individual or enterprise that has important projects to execute in Nigeria relies on the competence of technicians from neighbouring countries to draw his workforce from. It therefore behoves on the stakeholders to embrace technical education and fine-tune all the other parameters required to strengthen both the technological and university education. Although technical education produces the apparatus for running the technological and engineering education, the latter produces new technology while the formal acts as the interface between the technical and the engineering education. Technicians, technologists and engineers are produced from technical colleges, polytechnics and universities respectively. The availability of these personnel in the right proportions in an organization promotes rapid industrialization in the presence of enabling environment and appropriate infrastructure. The thrust of research in engineering education is the generation of scientific knowledge and application of it in the production of scientific and technical labor, the development of material processing systems, the production of machinery and equipment for general and specialized functions and the application and service needs of the society. Research is generally directed at discovering, creating and adding to a pool of knowledge. Such research results are disseminated by researchers to the industry through the training of the students by incorporating the research findings in their classroom activities thus enriching both teaching and learning situation within the department; and the students are later employed to work in the industry where id eas are shared among the other employees. The findings can also be transferred directly to the industry via seminars, workshops etc. This promotes the development of endogenous technology and advancement in productivity, Falade (2004). The difference between a developed, rich and prosperous country and the developing or underdeveloped country is the difference in their level of scientific, engineering and technological advancement

\section{Discussion}

Nigeria was a forerunner in the development and exploitation of technical education for the improvement of the life of her citizens. In the pre-colonial era, the workforce of the country was technical education driven. The evidence of the assertion can be seen in decayed infrastructure called Federal Government Technical College, Yaba which glory had been subsumed by that of Yaba College of Technology, which shares the same fence with the institution. In 1960s, 1970s and early 1980s for instance, there were standard automobile, carpentry and metalwork workshops, which provide qualitative services at modest prices to members of the populace who appreciate the quality of services they offer. The Federal Government of Nigeria, recognizing the prospect of Technical education formulated a policy that made it mandatory for every State and Local Government in Nigeria to establish at least a Technical College in its domain. Most State government conformed to the policy; there was no record of any Local government that executed the policy largely due to their lack of political will or their ignorance of the import of technical education. Although compliance with the policy statement was not total, the impacts of the Technical colleges were felt and the economy was better it. The technical education at that time provided the knowhow for the low-level labor the purpose for which it was meant to achieve. However, funding, as it is the case with any other institution owned by government was grossly inadequate causing the fortune of technical colleges to dwindle. The advent of the Colleges of Technology/Polytechnics and the Universities with multifarious areas of specialization designed to cater for middle level and high level manpower respectively have exacerbated the success records of technical colleges as the attention of governments at various levels shifted from the low level manpower production. Technical 
education is no doubt very expensive so it requires strong political will to for people to put the money where their mouth is. Also at the policy formulation level majority of the technocrats who are in charge of policy formulation don't have technical education background, so they tend to concentrate more on their fields at the expense of technical education so when experts are required they seldom invite experts on technical education and consequently, technical education is rarely talked about. That foreigners constitute the large chunk of the technical labour force in Nigeria portends that we lack leadership and adequate labor in that area. It also portends that we lack planning, that is based on manpower cannot be adequately done especially when you remember that many of the national developmental plans have failed, not as a result of inadequate paper work, but as a result of inadequate manpower particularly in the middle level cadre. It is a pity that technical education, with all its potential, has not been fully realized in Nigeria and the omen is not good, Aina (2011). Very recently, giant strides were taken by government at various levels to resuscitate technical education, some of which were considered below, viz::

Committee on repositioning technical education in Nigeria: The cycle of technical education which must translate to development must be based on the tripod stand with the three levels of education as its legs such that the university education provides the pedestal for modelling an idea as conceived by science, design the model based on the model and interpret the design to the technologist(s); the product of technological education that supervises the execution of the design with the technicians, product of technical education as the foot soldiers who carry out the actual execution under strict supervision of the technologist. Shortly after his election in the year 1999, President Olusegun Obasanjo, who seemed to have recognized that there was a missing link in the education cycle of development commissioned a Committee on repositioning technical education in Nigeria; the committee that was headed by Professor Olu Aina came up with a blueprint, which was a terrific report that would have been a springboard for the realization of technical education in the country; unfortunately, like several other reports, it languished on the shelf for a very long time until sometimes in year 2003 when the Education Trust Fund dusted the report for possible implementation. The substance of the attempt has not been translated into tangible development; it hoped that efforts would transform to visible result in the nearest future.

Seminar on repositioning of education: Driven by the hue and cry about decadence in education in the country, stakeholders in education were making contributions in their own ways; one of such stakeholders is the National Assembly; about three years ago, the National Assembly organized a seminar with the aim to reposition education where notable stakeholders in technical and technological education presented papers and the import of technical education was brought to the fore as a prerequisite to Nigeria's pursuit of developmental goals and consequent attainment of vision 20:2020. If action could match words from such fora then Nigeria's hope of achieving the much-touted Millennium Development Goals (MDGs) will come alive. Nevertheless, no visible action succeeded the seminar except further disintegration that had further aggravated the state of education in Nigeria. For instance, the epileptic power supply that had crippled the manufacturing sector in the country had not been traced successfully to inadequate power generation but there is clear evidence that the technical insufficiency of the staffers of technical departments of PHCN contributed to the systemic malaise of the organization. In addition, the fact that corruption in PHCN matches that of the Nigerian Police, according to Transparency international, is a product of technical incompetence. Competent staff has integrity. The reason why the members of the three arms of the military namely; the Nigerian Air Force, the Nigerian Army and the Nigerian Navy have not found dignity in massive corruption as opposed to their counterpart in the Nigerian Police is attributable to discipline born out of competence. An engineer in training without input from vibrant set of technicians is a disaster. An engineering design without proper implementation by unlettered labourer results in underdevelopment.

Giant stride by State Government: The present government of Osun state is fascinated about skill development especially for the youth and she is prepared to facilitate the process of achieving a hundred percent skill acquisition for her teaming youth in a scheme tagged "Life Skill", Aina (2011). To this end, the administration of Governor Aregbesola had refurbished the state government owned technical college in Osogbo and he is willing to replicate the action in all other such institutions in the state. Nevertheless, the situation will remain unchanged if competent staffs are not sourced to provide the necessary impetus needed to achieve the desired goal. In addition, there must be an enduring policy to back the actions taken today to procure the future for the effort. Lagos State is one state that is striving to live up to its slogan, "Centre of 
Excellence" by aggressively embarking upon reconstruction of her educational structures in general, replacing dilapidated building by mega-structures, introducing functional cancelling departments in all secondary schools to mention but a few. However, very little has been done in the area of technical education in the state.

The 6-3-3-4 System of Education: According to Professor Olu Aina the 6-3-3-4, system of education did not succeed but it did not fail completely. The system fell short of the level of expectation of the planners due to the following factors:

- Lack of political will

- Improper planning, and

- Inadequacy of data

He opined that, within a few years of the commencement of the programme, there was an explosion in school population far in excess of expectation and what was planned for. For instance, classroom that was built for 20 was housing 50, so there were 30 children who could not find seats thus reducing the contacts between pupils and teachers from 30 to 1, to 50 to 1 . Other problems that robbed the system of success include "poor planning". For example, there was no provision for the laboratories/workshop to provide shelter for the multimillion equipments the government supplied to various secondary schools at the commencement of the programme. I was privileged to serve in a secondary school in Ikere-Ekiti on the National Youth Service Corps (NYSC) scheme. In the school where I serve, all the equipment supplied to the school for the implementation of the Junior Secondary School (JSS) scheme had rotten for lack of shelter. There was not a single technician of technologist on the staff list of the school, which translate to lack of labor to operate and maintain the equipment in case the systems were to be put to use. It became clear that the progenitors of 6-3-3-4 system of education might not be sincere with the programme after all.

\section{Conclusion}

South Korea was at a time at the same level of development with Nigeria and India but they are far ahead of Nigeria now because they paid attention to technical education. The advanced nations of today were Neolithic communities of yesterday. Nigeria is not an underdeveloped state since it has surpassed the Neolithic stage; just that it is still a toddler at 50. Rather than dissipating all its energy on political zoning formula the ruling class should summon the political will required to foster rapid development of purposeful engineering technological education with credible impetus garnished with dedication, determination and devotion.

Recommendations: Nigeria is a nation of oddity where the unconventional is the convention. Nevertheless, it is recommended that:

- In the scheme of development, the role of the three tiers of engineering education namely; technical education for technician, technological/polytechnic education for technologist and university education for engineers should be clearly defined so that whatever the background of the technocrats in charge of technical education at any point in time, the substance of the project will not be altered.

- The current trend where emphasis is placed on paper certificate has eroded the ethic of commensurate reward for hard work. The university certificate is fast become of less quality to the secondary school certificate of the 70s because people who seek degree do so as an end and not as a means to an end. Those who do have business being in the university are seeking to graduate with a first class. Someone whose destiny is contented with technician certificate will definitely be a failure with First class in Electrical engineering.

- In line with the mind of the government of the USA, it is recommended that the document policy on engineering technology education as summarized in this paper be adopted wholly with amendments to accommodation our peculiar situation. However, the peculiarity should not be accommodative of corruption and other vices that share the peculiarities of corruption.

- The federal government should stop the award of licence to corrupt official and organizations under any guise to establish universities whose products cannot compete with technicians from India. They 
should rather concentrate on the technician cadre development for now so that the ratio of technician/technologist to engineer can be improved upon.

- Existing federal universities should be audited and well funded. Programme rationalization should encourage in line with strength of existing institutions and the peculiarities of geographical areas.

- Establishment of new polytechnics and universities should be stopped forthwith to pave allowance for adequate planning and funding of existing ones. The current where government just establish an institution of higher learning to satisfy geographical distribution is not profitable in anyway.

- After all the aforementioned are properly implemented, the federal government should design a viable blueprint that will serve as a springboard for national development.

\section{References}

Aina, O. (2011). India, South Korea ahead of Nigeria because of quality technical education. Saturday Punch, 7085(1575), 18-19.

Ajibola, O. O. E. (2011). An expository analysis of problems and prospects of engineering education in Nigeria. International Conference on Innovations in Engineering and Technology, University of Lagos, Akoka, Yaba, Lagos, Nigeria. 842-850.

Alabe, M. O. (2009). Engineering Education in Nigeria,1.

Britannica. (2008). http://www.britannica.com

Dike, V. E. (2009). Technical and vocational education: key to Nigeria's development. Nigeria Villa. 1-15. http://www.nigeriavillagesquare.com/index.php?view=article \& catid.

Engineering Technology Education. (1985). Engineering education and practice in the United States: Foundations of Our Techno-Economic Future. Washington D.C. National Academy Press. http://www.nap.cdu/openbook0309036321/html/22.html. Copyright 1985.

Falade, F. (2004). Focal Point in Engineering Education: Research, Development and Transfer of Technology The Nigeria Experience, Proc $2^{\text {nd }}$ African Regional Conference on Engineering Education, University of Lagos, Nigeria $20^{\text {th }}-22^{\text {nd }}$ September, 2004, $151-160$.

Falade, F. (2010). Engineering education: bedrock of industrialization. COREN Workshop on Teaching and Learning Tools, 5 - 7, October 2010, Abuja, Nigeria.

Wikipedia (2011). Reward system. Wikipedia, the free encyclopedia. en.wikipedia.org/wiki/Reward System. 